\title{
Words Under Pressure: Translation in the Context of Search Engine Optimization
}

\author{
Andrei V. Achkasov* \\ St. Petersburg State University \\ 7/9 Universitetskaya nab., St. Petersburg, 199034, Russia
}

Received 12.11.2014, received in revised form 06.12.2014, accepted 21.01.2015

\begin{abstract}
The key activities in multilingual search engine optimization (SEO) imply the expertise of the linguistic behavior of users (search queries), keyword translation, contrastive cross-linguistic analysis of keywords, translation into the target language under SEO restrictions and off-site copywriting in the target language. As a result, in the context of website translation and localization, SEO imposes additional restrictions and demands on the translation workflow and strategies that contradict conventional views on translation quality and textuality. SEO and translation thus represent conflicting activities which nevertheless have to be performed within website localization projects. At present, the localization industry is developing new translation and language-related strategies and needs SEO trained translators and linguists. SEO linguistics and SEO translation is an emerging challenge for both Translation Studies and institutional translator training.
\end{abstract}

Keywords: website translation, website localization, search engine optimization, SEO translation, multilingual SEO, SEO linguistics.

Research area: philology.

\section{Introduction}

There is no doubt that translation industry and language-related technology influence Translation Studies and academic translator training. It is also obvious that institutional translator training is always one step behind the real life translation technology and practice. Acknowledging this fact, I refer only to technology and practice, and I am far from giving any kind of general priority to the translation industry over Translation Studies and institutional training. The industry is, in many ways, miles behind universities. Consider, as an example, the attempts that the industry undertakes to imitate institutional training and genres of academic writing.

I believe that translation industry extends the scope of translation-related jobs and provides effective training in advanced technical skills, while the main competitive advantage of the university-level translation training is the high standard linguistic competences, which cannot be acquired throughon-the-job practice. However, the conflict between the academics and the industry is essential, and there is a good deal of sentential prejudice and arrogance coming from both sides. In 2014 A. Pym reproduced the arguments that he made in 2006 concerning the issue of "industry

(C) Siberian Federal University. All rights reserved

* Corresponding author E-mail address: a_v_achkasov@mail.ru 
vs academics" in relation to localization. Here are the first two reasons for his pessimism: "First, academics tend not to take the localization industry seriously because they, the academics, have established themselves in apparently stable professional fields (technical translation, literary translation, conference interpreting) and see no reason to change. The new kid on the block seems to offer no more than hype and money, without the humanistic discourses still treasured by ageing teachers ("translation helps create dialogue and peace among the peoples of the earth", and so on). Second, localization experts mistrust academics because they think that they, the academics, know nothing about the industry, or about any real-world industry for that matter. And often they are quite right" (Pym, 2014: 45).

Within a longer span of time, institutional training, Translation Studies and the translation industry seem to approach each other. Who would have thought some 20 years ago that all those "digital gimmicks" like translation memories, terminology management tools and electronic corpora would be a "must-know" for translators and a subject of academic theorizing? At present, university-level translation training programs include courses on computer-aided translation (translation memories, terminology management, corpus-based information retrieval) and localization-related courses that yet do not seem to address localization as a complex of tasks.

Translation in the context of search engine optimization (SEO) is a new challenge for academic research and translation training. Just google "SEO translation" and you get "SEO translation", "SEO-centric translation", "SEOfriendly translation", "SEO-trained translators", "SEO web translation", "multilingual SEO", "SEO/Meta Translation", "Integration of SEO into the translation process", "SEO linguistics" as well as "SEO for translators" and "SEO for linguists". It is obvious that SEO industry is in demand of professional linguists and translators and that, at the same time, it is demanding new competences from them. In response to these needs professional freelance translators focus on these types of work in their profiles, including HTML basics and specialized software for keyword research, and produce a vast variety of SEOrelated terms that describe their competences. A counterpart trend comes from the SEO industry that utilizes linguistic terminology and from SEO-related blogs that explore the possibility for SEO experts to become linguists. The academics seem to be behind the trend again. At present, SEO has not been taught in translation training programs and "despite the status it enjoys within the internet marketing sector, SEO has effectively been neglected by Translation Studies up to now". (Jude, Massey, 2011: 152)

\section{"Content is the king"}

This article primarily addresses the academics, and therefore a short introduction to SEO would be relevant. In short, SEO is "improving a website in order to attract search engine crawlers" (Ledford, 2009: 492). In other words, it is not enough to have a good website; it should also be ensured that the site will be found in search engines and presented in search results (the higher the better) for relevant search words and phrases.

Let alone technical features, SEO is very much about words, content (texts), semantics and the linguistic behavior of users. One of the myths is that SEO is primarily aimed at search engines. Of course, SEO is aimed at improving the visibility of a website in search engine results, and thus SEO strategies have to comply with the criteria the search engines use to rank web pages. On the other hand, search engines are designed to satisfy the needs of human users and therefore both page ranking and SEO are closely related to 
how language is used in relation to search, i.e., to human linguistic behavior. "Content is the king" is the golden rule of SEO, meaning that only quality content brings users to the website.

The analysis of search queries allows identifying and ranking keywords related to particular products or topics. Using such keywords through a website will comply with users' "search language" and can potentially generate traffic. Simply put, appropriate keywords should be used when writing texts for a website. For example, the phrase "pre-owned cars" might be preferred for terminological or stylistic reasons, while customers are " 45 times more likely to search for "used cars" than "pre-owned cars" so obviously, you shouldn't be using that term on your site" (Autorevo, 2014).

Now suppose that a business is being launched; for example, a translation agency. Broad terms like "translation", "professional translation" or "translation agency" would obviously be relevant keywords for the website. On the other hand, there are too many competitors using the same keywords, so they would produce a minimal effect. Due to the competition for keywords, they lose their value/strength, and hence some preliminary research is needed before deciding on the keywords to be used. One way to solve this problem is to target less competitive keywords and "long-tail keywords" (longer and more specific search phrases). In case with a translation business instead of "translation agency" a "translation agency + local name (city, district)" might be used, because when looking for a translation service people are likely to look for a local office. For instance, a UK agency "PS Translation" (http://www.pstranslation.co.uk), as an example, uses, among others, such keywords as "translation services in cambridge", "translation agency in cambridge", "translation services in east anglia", "translation agency in east anglia". It is also possible to focus on specific competitive features of a business, for example on genres of translation. In the present-day Russian market keywords "translation of academic articles" or "translation for scientific journals" (in Russian, of course) could be potentially effective due to the increasing publishing activity of academics.

Keywords should be evenly distributed through the content, but using keywords in the texts only is not enough. Search engines assign different weight to keywords placed at different locations on the webpage. Keywords should be used in headings, anchor text (hyperlinks), alt tags (invisible descriptions of images), meta tags (meta keywords - invisible keywords for search engines; meta description - a short text used to describe a webpage in search results), etc. All these technical terms might be confusing for a linguist, and "many people think that for learning SEO you need to have technical knowledge which is completely wrong assumption in the market" (School of Digital Marketing, 2014). In fact all that a translator needs to know to get started is HTML basics, which is simpler than using MSWord, and some essential knowledge of SEO.

This is a brief outline of how linguistic content of a website should be designed in order to satisfy search engines. User demands, on the other hand, bring us back to the linguistic quality of the content, for this is the user who decides to leave a website or to browse it, and, eventually, "to buy or not to buy". It means that the content should be relevant, informative, natural, etc. Producing and mapping quality content with SEO in mind is a job that demands professional writing skills and linguistic competences.

\section{SEO and translation}

Now back to translation. Website localization is basically designing a site in the target language that is "linguistically and culturally appropriate to the target locale" (Esselink, 2000: 3) or "the process of modifying an existing Website to 
make it accessible, usable and culturally suitable to a target audience" (Sandrini, 2007: 175). Suppose that "professional linguists who are native speakers of the target language as well as experts in the relevant industry will creatively rework the original copy so that it successfully conveys the intended message" including "word play, idiomatic expressions, colloquialisms, word choice, humor and level of formality" (TransPerfect, 2014). Suppose also that other elements of the website, such as images, colors, layout, fonts, dates, measures and forms are also adapted to the target locale. Now the adapted version of the website is ready to meet the needs of users who speak a different language and live in a different cultural, social and economic context. And still, no matter how informative, natural and relevant the content may be, the website still needs SEO, because customers in the new target market use a different search language when looking for similar products, services or information. When looking for "used cars", Russian customers might use a similar search phrase («подержанные машины» "poderzhannye mashiny") or they might not. In fact, Google returns similar number of exact hits for «подержанные машины» ("poderzhannye mashiny"; "used cars") and «машины с пробегом» (“mashiny s probegom”; "cars with mileage"). The keywords in meta tags at the main pages of AutoTrader (USA; www. autotrader.com) and AARON (RF; aaron-auto.ru) represent the difference:

$<$ meta name="keywords" content $=$ "used cars, used cars for sale, cars, cars for sale, new cars, AutoTrader.com, Auto Trader, AutoTrader" 1>

$<$ meta name="keywords" content="купить автомобиль с пробегом, куплю автомобиль с пробегом, куплю подержанный автомобиль» />

Another aspect of choosing keywords is that users often misspell search words and use ungrammatical search requests. If such deviations from language norms are systematic, they might be utilized as keywords. As a result, "optimizers are sometimes known to flout rules of spelling and even grammar in order to maximize the probability of a website ranking high in the list of search engine users who mis-spell words and apply faulty syntax (Jude, Massey, 2011: 151), Another instance of this issue is observed by Spinner (Spinner, 2014: 20), who notes, that "Japanese frequently search in Japanese with English mixed in. In this case, you want to match their search inquires with the mixed keyword phrase on your page". Moreover, in a new market a company will have new competitors. In terms of SEO, it means competition for keywords. Keyword translation would simply miss the point of SEO.

The two-stage "localization-to-SEO" scenario is time- and money-consuming. "Linguistically and culturally appropriate" content may need rewriting under pressure of SEO factors, and then it may need another round of linguistic polishing. A more effective and less costly approach would be to translate and localize "with SEO in mind". Localization companies actively advertise this kind of work and, basically, make two strong points: (1) localization and SEO translation are complementary but different services (2) SEO should be considered alongside with website localization/translation. Terminology for this type of service may vary ("SEO translation", "SEOlocalization”, "SEOWeb Translation", "multilingual SEO”, "translation for SEO", etc.) while the key points remain the same. Typically, the service description goes as follows: "SEO-Localization service which combines translation with search engine optimization to provide accurate website translations and SEOfriendly content. SEO-Localization is carried out by professional translators and native SEO specialists to deliver accurate, relevant content of the highest quality" (Webcertain, 2014). 
The span of this article allows me only to give a glimpse of the bundle of issues related to SEO translation. So far I have mentioned onsite SEO techniques related to the content of the website. There is also off-site SEO, which includes creating backlinks to the website using social media, blogs, landing pages (standalone webpages to which visitors are directed via advertisement), press releases, etc. Writing for off-site SEO within a localization project is, obviously, not a translation job. In a broader sense "copywriting in the target language" is "an alternative to translation" (Lakó, 2013: 709) and represents another level of localization. In this perspective, producing texts in a target language that are closely related to the adapted version of a website using the same target keywords is a spinoff of the translation job.

I have not mentioned many other issues relevant to SEO translation. SEO is pagespecific; it is performed for each page separately, and not for the entire website. SEO is an iterative process; initial SEO efforts are followed by the monitoring and evaluation of resulting rankings, and then are followed by another round of SEO. Even if the rankings are fine, they may change due to the increasing competition for keywords and continually changing ranking criteria. Thus, SEO is an ongoing process. Working on SEO updates can be compared with working on website updates within a website localization project.

\section{Who SEO-translates?}

Everything said above brings us to another aspect of the localization-translation-SEO problem. The localization industry generally assumes that SEO translation/localization "is carried out by professional translators and native SEO specialists". But what is the actual translators' and linguists' share in the overall process of SEO translation?
At the first glance the workflow in multilingual SEO is as much fragmented as it is in localization projects. There is a set of tasks that are performed by SEO experts. They are pre-SEO analysis (competitor reviews, technical audit), identifying SEO tools, setting up the project, working with the code (using country and language codes, structuring URLs, building link hierarchy), geo-targeting ("geographical SEO", delivering different content to users in different geographical locations), etc. Languagerelated tasks, including translation, adaptation, revision and copywriting, are distributed between different experts. However, most of the types of work performed through SEO translation projects involve linguistic competences. Keyword research, analysis of competition for keywords and finding "keyword niches" is the core of the socalled "SEO linguistics". It does not only involve the expertise of the linguistic behavior of users. In a multilingual SEO project it includes contrastive cross-language analysis of keywords, and as an initial step, keyword translation. Producing and rewriting texts (both on- and off-site) with a view to both linguistic quality and SEO is not a trivial task. The terms "SEO-trained linguists" or "SEO-trained translators" are motivated by the actual needs for linguistics-related competences in the field.

As a part of website localization projects, multilingual SEO represents a shift to a narrower and more integrated segment in terms of language-related competences. It does not mean that SEO translation is or should be performed by a single SEO-trained linguist. The level of integration is not measured by labor division in a real-life multilingual SEO project; it has to do with the types of competences needed to perform particular tasks. It seems to be a common view that there are translation competence(s), but in translation projects different types of work, such as terminology management, translation, editing, 
proofreading, quality assurance, etc., are done by different people. Translation projects are highly fragmented in terms of labor division, but not in terms of the range of competences. The same seems to apply to multilingual SEO and is in line with "holistic SEO" strategies.

\section{Theoretical implications}

It is commonly overlooked (or intentionally ignored by the localization industry) that website translation and promoting sites in search engines, that is, translation and SEO, are essentially conflicting activities. The first point of the conflict concerns managing keywords in the source and target languages. "Keywords do not translate so content which has been worked on for SEO purposes will lose the SEO benefit the moment they are translated" (Search Engine Land, 2014). Finding appropriate keywords is not a matter of translation. In their marketing materials, localization companies often try to bridge the gap between translation and SEO by treating keywords within the scope of multilingual terminology management. According to this, initial keyword translation is followed by (or paralleled with) keyword research in the target language, thus resulting in a bilingual keywords base. Using this base translators are supposed to produce the target text that would meet the SEO objectives. In real projects this additional splitting of the workflow does not produce the desired results and is declared in advertising materials for marketing purposes. Keywords in different languages rarely have one-to-one relation, and, moreover, the target keywords may represent a unique non-equivalent set of phrases and they do not necessarily fit into the corresponding segments of the target text.

Another aspect of the conflict between translation and SEO stems from the conventional views on translation equivalence and translation quality. SEO-driven positioning of keywords in the target texts may involve various kind of text rewriting that cannot be accounted for in terms of linguistic and cultural appropriation. Thus, the relation between source and target texts in the context of SEO becomes increasingly blurred and 'decisions in terms of 'equivalence' are no longer sufficient in themselves in an online environment" (Schiller, 2008: 59). Moreover, it has already been mentioned that optimizers often use misspelled words and ungrammatical phrases. Jude and Massey also observe that "the constraints imposed by keyword positioning and density lead to the creation of a target text which fulfils the client's brief, but which fails to meet the quality standards conventionally associated with textuality". (Jude, Massey, 2011: 151-152).

SEO is not just another factor in translation. Interpretation of the process and the results of producing target texts under pressure of SEO constraints thus become problematic in terms of Translation Studies. Jude and Massey (Jude, Massey, 2011) undertake such an interpretation in terms of Holz-Mänttäri's translatorial action model and its further developments, viewing the search engine as a "non-human actor" that participates in the communication process as a selective mediator. (Jude, Massey, 2011: 151). This approach provides one possible model for further conceptualization of SEO-related cross-lingual transfer practices. However, the abovementioned model might not be taking in account, that SEO is an ongoing process and that "over a period of time the keywords will change in relevancy as search terms evolve and the relevancy of your product range changes" (Damani, R., Damani, Ch., Rarbo, 2006: 55). The target texts are thus unstable entities that are likely to be modified and eventually rewritten. Moreover, we still need to take into account off-site copywriting in the target language, that is, producing extensions of the on-site target texts using the same keywords 
and phrases. They may be both translations of source texts or relatively original texts. There is obviously some kind of cross-language relation between the two bodies of on-site and off-site texts in the source and the target languages, and yet this is not the relation between the original and the translation. Schiller (Schiller, 2008) accounts of this relation in terms of Hervey, Loughridge and Higgins (2006), where the term equivalence "refers to a translation methodology that avoids 'an absolutist attempt at maximizing sameness in things that are crucially different (ST and TT), in favor of a relativist attempt at minimizing dissimilarities between things that are clearly understood to be different". (Schiller, 2008: 59). It might be objected that the initial motivation for SEO translation is the focus on differences, and that similarity in digital marketing is measured by non-linguistic criteria, such as by search rankings and sales rates.

A different approach to conceptualization of SEO and translation is hinted by information studies. Search behavior as a subtype of a linguistic behavior has recently become an issue of research in information management and in linguistics. This line of study in particular covers cross-linguistic and cross-cultural aspects of search behavior as well as social, age and gender issues of linguistic behavior. While surfing the web for the same or similar product or information, users in different locales prefer different search phrases. Such differences vary in lexical choices, their length, grammaticality, and strategies of modifying search queries. The regularities and contrasts in search behavior are utilized in information interaction/retrieval as well as in multilingual SEO and website localization. For linguists such research provides a new type of a dataset and new grounds for contrastive studies. Moreover, user queries have become a standalone issue of study. There are claims that web search queries are evolving into a protolanguage or "have evolved into a language of their own" (Saha Roy, Ganguly, Choudhury, Singh, 2011: 5), and that search queries "have a unique structure, which is more complex than just a bag-of-words, yet simpler than a natural language" (Saha Roy, Choudhury, Bali, 2012: 58). Because linguistic behavior of users is a key factor in SEO translation activities, the cross-language relation between the bodies of texts produced within multilingual SEO projects might be accounted for in terms of functional and semantic contrasts.

\section{Conclusion}

At present, there is a growing awareness in academic research that "the importance of keywords in the language of the web is one of the most interesting phenomena for linguists and translators alike and the lexical level of online content provides a good vantage point for some observations on the nature and quality of web translation" (Cappelli, 2008:102). And, as yet, there is no model for a systematic interpretation of SEO-related translation practice.

SEO translation is an emerging challenge for both Translation Studies and training. It has been observed by both the industry and the academics that SEO translation involves linguistic competences. The core activities in SEO translation are the expertise of the linguistic behavior of users, contrastive crosslanguage analysis of keywords, keyword translation/localization, producing target texts under SEO restrictions, and off-site copywriting in the target language. As a result, in the context of website localization, SEO imposes additional restrictions and demands on the translation workflow and translation strategies that contradict conventional views on translation quality and textuality. At present, the scope of SEO linguistics and SEO translation has not been covered in Translation Studies and translator training programs. 


\section{References}

1. Autorevo, Don't Get Used by the Pre-Owned Game: Do Keyword Research. Available at: http://www.autorevo.com/blog/keyword-research (accessed 10 September 2014).

2. Cappelli, G. The translation of tourism-related websites and localization: problems and perspectives. A. Baicchi (eds.). Voices on Translation, RILA Rassegna Italiana di Linguistica Applicata, Roma: Bulzoni Editore, 2008, pp. 97-115.

3. Damani, R., Damani, Ch., Rarbo, D. Online Marketing. Imano plc., Imano inc., 2006. 119 p. Also available at: http://issuu.com/imano_ltd/docs/online_marketing (accessed 27 October 2014).

4. Esselink, A. Practical Guide to Localization. Amsterdam \& Philadelphia: John Benjamins, 2000. $488 \mathrm{p}$.

5. Hervey, S, Loughridge, M \& Higgins, I. Thinking German translation: A course in translation method-German to English. 2nd ed. Routledge, London, 2006. 243 p.

6. Jude, P., Massey, G. Machines as participants in the communication process: the implications of SEO for translation. Evolution der Informations gesellschaft. Markenkommunikation im Spannungsfeld der neuen Medien. Cary Steinmann (Hrsg.). VS Verlag für Sozialwissenschaften . Springer Fachmedien Wiesbaden GmbH, 2011, pp 143-155.

7. Lakó, C. Benchmarking localization, a content marketing perspective. The Proceedings of the European Integration-Between Tradition And Modernity Congress. Editura Universității "Petru Maior", vol. 5, 2013, pp. 706-712.

8. Ledford, J.L. Search Engine Optimization Bible. Wiley Publishing, Inc., 2009. 528 p.

9. Pym, A. (2014) Localization, training, and instrumentalization. Translation Research Projects 5. Eds. Esther Torres-Simon and David Orrego-Carmona. Tarragona: Intercultural Studies Group, 2014. pp. 37-50. Also available at: (accessed 21 October 2014).

10. http://isg.urv.es/publicity/isg/publications/trp_5_2014/TRP5_2014.pdf

11. Saha Roy, R., Ganguly, N., Choudhury, M., Singh, N.K. Complex Network Analysis Reveals Kernel-Periphery Structure in Web Search Queries. 2nd International ACM SIGIR Workshop on Query Representation and Understanding. QRU, 2011, pp. 5-8.

12. Saha Roy, R., Choudhury, M., Bali, K. Are Web Search Queries an Evolving Protolanguage? Proceedings of the 9th International Conference on the Evolution of Language (Evolang IX) March 13, 2012, pp. 58-63.

13. Sandrini, P. Localization and Translation. LSP Translation Scenarios. Selected Contributions to the EU Marie Curie Conference. Vienna, 2007. Ed. Gerzymisch-Arbogast, H., Budin, G., Hofer, G. MuTra Journal, vol 2, 2008, pp. 167-191.

14. Search Engine Land. A Glossary of 15 Really Useful International Search Marketing Terms. Available at: http://searchengineland.com/a-glossary-of-15-really-useful-international-searchmarketing-terms-121315 (accessed 15 October 2014).

15. School of Digital Marketing. SEO course. [Advertising materials] Available at: http:// seotraininginstitutespune.co.in/seo-course-content/ (accessed 15 October 2014).

16. Schiller, Annette (2008) Aspects of cohesion in web site translation: a translator's perspective. [PhD thesis] Dublin City University. School of Applied Language and Intercultural Studies. September $2008 \mathrm{http}: / /$ doras.dcu.ie/610/1/Annette_Schiller_DCU_PhD_Dissertation_2008.pdf

17. Spinner. R. Global, Multilingual SEO Including SEM, PPC, SMO and Usability.

$$
-207-
$$


18. CreateSpace Independent Publishing Platform, 2014. 78 p.

19. TransPerfect. International Search Engine Optimisation and Marketing. [Advertising materials] Available at: http://transperfect.co.uk/pdfs/TransPerfect_SolutionBrief_ISEO_UK.pdf (accessed 15 October 2014).

20. Webcertain. SEO-Localisation [Advertising materials] Available at: http://webcertain.com/ seo-localisation.html (accessed 15 October 2014).

\title{
Перевод в условиях поисковой оптимизации
}

\author{
А.В. Ачкасов \\ Санкт-Петербургский государственный университет \\ Россия, 199034, Санкт-Петербург, \\ Университетская набережная, 7/9
}

\begin{abstract}
Локализачия и перевод вебсайтов в качестве обязательного компонента включают поисковую оптимизацию на языке перевода. Основные виды деятельности, связанные с поисковой оптимизацией, предполагают владение лингвистическими и переводческими компетенциями и включают анализ поисковых запросов на языке перевода, перевод ключевых слов, контрастивный межъязыковой анализ ключевых слов, перевод материалов сайта с учетом требований поисковой оптимизации. Как следствие, в процессе перевода и оптимизации вебсайтов требования поисковой оптимизации создают дополнительные ограничения, которые противоречат нормативным требованиям к качеству перевода. Таким образом, поисковая оптимизация и перевод в значительной степени противоречат друг другу и все же должны осуществляться в рамках одного проекта. Индустрия локализации вебсайтов создает новые стратегии перевода и нуждается в переводчиках, имеющих подготовку в области поисковой оптимизации. Перевод в условиях поисковой оптимизации является очередным вызовом для переводоведения и программ подготовки переводчиков.

Ключевые слова: перевод вебсайтов, локализачия вебсайтов, оптимизачия сайтов под поисковые системы, перевод в условиях поисковой оптимизации, многоязычная поисковая оптимизация, лингвистические аспекты поисковой оптимизации.
\end{abstract}

Научная специальность: 10.00.00 - филологические науки. 